\title{
Chapter 5 \\ The Internet as a Small Business E-commerce Ecosystem
}

\author{
Michael Buxton and Nigel Walton
}

\begin{abstract}
The purpose of this chapter is to analyse how the ecosystem concept can be applied to small businesses and how the Internet and e-commerce can help SMEs harness the required resources to enhance their competitive performance in the marketplace. The chapter will investigate the wide variety of e-commerce applications that are available to small businesses to help address the issue of limited resources. It will provide an ecosystem map illustrating how each functional area of a small business can utilise Internet e-commerce applications to enhance their resource base. The chapter also explores the opportunities and threats that the e-commerce ecosystem model poses for small, medium-sized enterprises (SMEs). This is based upon empirical research consisting of three focus group interviews undertaken with small and medium-sized retail service firms located in the Herefordshire and Worcestershire regions of the United Kingdom in January-February 2014.
\end{abstract}

Keywords Ecosystem $\cdot$ Internet $\cdot$ Resources $\cdot$ E-commerce $\cdot$ Applications

\subsection{Business Webs and Ecosystems}

During the 1990s, globalisation and the introduction of new technologies such as the Internet created new opportunities for businesses to increase their competitiveness by reducing costs and increasing productivity through specialisation within their operations. This was achieved through outsourcing previous 'inhouse' processes to other firms which therefore allowed businesses to specialise in areas where they had a particular competitive advantage (Poon and Jevons 1997;

M. Buxton · N. Walton $(\bowtie)$

University of Worcester, Worcester, UK

e-mail: n.walton@worc.ac.uk 


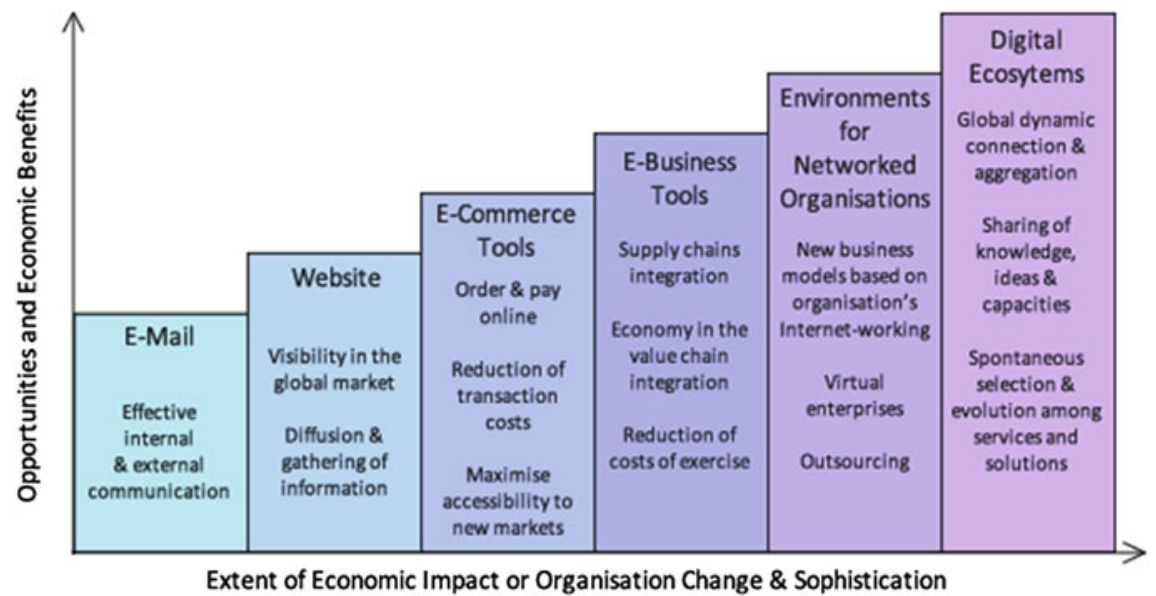

Fig. 5.1 The Cisco ladder of ICT adoption-modified to include digital ecosystems (Dini and Nachira 2007)

Johnson 2006; Fawcett et al. 2008). This movement towards the global supply chain consequently led to the development of networks or webs of interconnected businesses that can be referred to as business ecosystems.

Moore (1993) described a business ecosystem as an environment involving businesses that work cooperatively to support the development of new products, satisfy customer needs and create new innovations. These collaborative relationships between businesses in ecosystems was further supported by Hyeyoung et al. (2010), who defined a business ecosystem as an economic community, where companies who share symbiotic relationships work together in order to gain a competitive advantage.

The rapid and exponential growth of the Internet and e-commerce has resulted in multiple business communities or business ecosystems evolving which provide valuable resource inputs for smaller businesses that can be leveraged to good effect. This digital e-commerce ecosystem of Internet-based applications is illustrated in Dini and Nachira's (2007) framework below (Fig. 5.1).

The chapter will now analyse how the Internet and e-commerce as a digital ecosystem can provide a range of tools and applications to enable small firms and start-up ventures to operate asset-light business models.

\subsection{The Internet and the Small Business E-commerce Ecosystem}

A common threat to the survival of small businesses is the fact that they have limited resources. However, over the years, innovation and the development of e-commerce technology has given rise to new opportunities and economic benefits 
for businesses (as shown in Fig. 5.1). These technologies include e-commerce applications which provide businesses with the resources and opportunities to carry out business functions that would otherwise not be possible if they were performed in-house. In order to overcome the threat of limited resources, it is important for small businesses to consider the different e-commerce applications that are available to them that allow them to enhance or improve the efficiency of their existing resources. As suggested by Dini and Nachira (2007), many SME's are only at the email or website adoption stage of their digital ecosystem model (Fig. 5.1) and they are subsequently unable to spend time investigating or trialling different e-commerce applications. These findings were also endorsed by research recently undertaken with small retail service firms in the Herefordshire and Worcestershire regions. In order to investigate the e-commerce applications that are available to small firms and the potential benefits, it is important to consider the different business functions that may contribute to a small firm's operation. These consist primarily of the finance, marketing, operations and human resource functions. When these have been considered, the chapter will map out a small business ecosystem linking the different business functions to the relevant ecommerce applications that can be utilised to exploit opportunities for performance enhancement (the small business ecosystem map is illustrated in Fig. 5.2).

It is also important to appreciate that using an ecosystem approach when considering the available e-commerce applications helps to understand the interrelationship between resources. Therefore an ecosystem approach is appropriate because it permits examination of all the available resources that contribute to the overall success of the business therefore providing a holistic view. The chapter will now go on to consider some of the business functions shown in Fig. 5.2 and explore the different e-commerce applications that relate to them, starting with the finance function.

\subsection{Finance}

In order to examine the relevant e-commerce applications relating to this important area of small business resources; finance can be split into three separate business functions: raising capital, card payment processing and financial accounts.

\subsubsection{Raising Capital}

Small businesses often find it necessary to raise capital, whether it is for the financing of a new business or for the development or expansion of an existing one. According to the Bank of England (2000) and before the financial crash of 2008, the most common method of finance for small businesses was the use of retained profits from previous trading activities. However, this is not possible for 


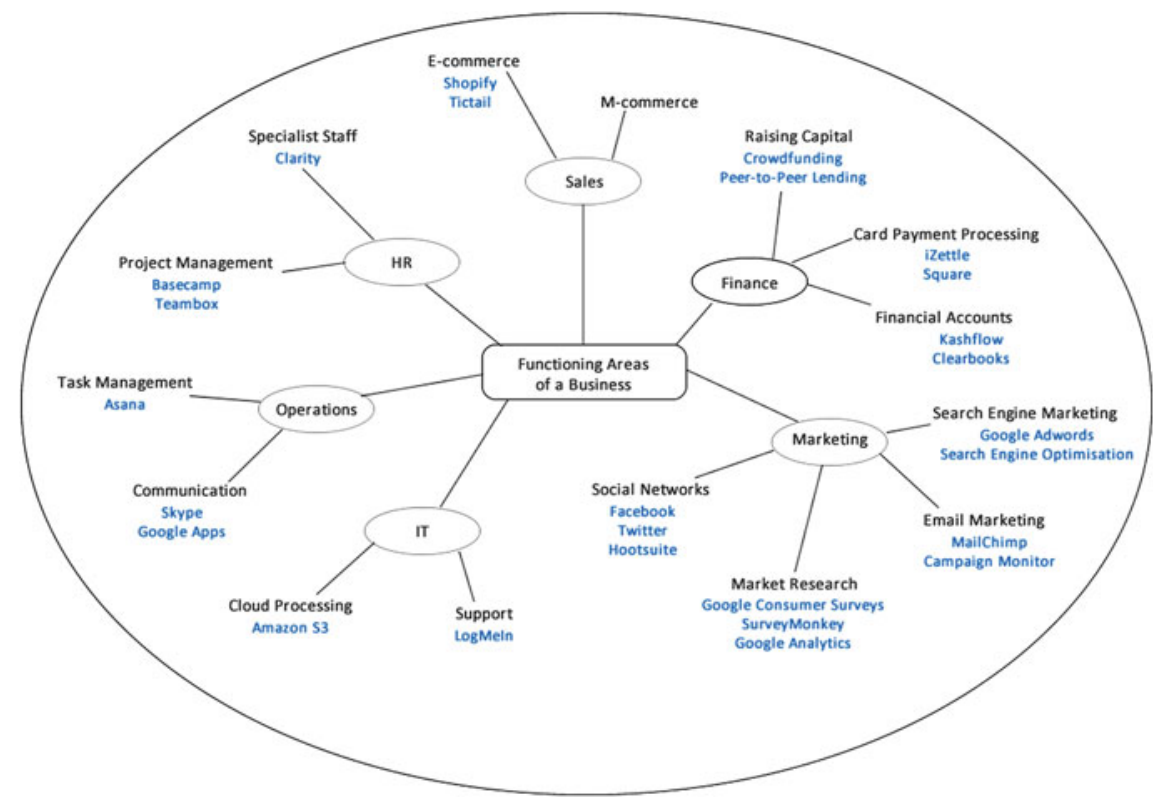

Fig. 5.2 An example of a small business e-commerce ecosystem

business start-ups or non-profitable firms. Therefore an important source of finance for small businesses comes from the entrepreneurs and owner-managers themselves, friends and family and external sources such as bank loans. However, some small businesses have been finding this difficult because not only has there been a reluctance to lend to high risk ventures (Cressy and Toivanen 2001), there has also been a general withdrawal of funding support following the credit crunch as high street banks chose to restructure their balance sheets instead of granting support to SMEs. Consequently, many small businesses are looking towards other sources of finance such as crowdfunding or peer-to-peer lending services to raise capital.

Crowdfunding, as explained by Ordanini (2009), is an initiative undertaken usually via the Internet in order to raise money for new projects by collecting investments from many different people i.e. the 'crowd'. Crowdfunding has become an effective method of raising money and has been used for many different projects including the funding of new bands, fashion designers, software applications, bars and non-profit organisations. Small businesses can therefore use crowdfunding as a way to raise capital through one of the many crowdfunding websites such as Kickstarter, Fundable or Indiegogo. It is however, important to note that certain websites have different rules about what type of project can be funded through their website. For example, Kickstarter can only be used for projects that relate to: art, comics, dance, design, fashion, film, food, games, music, photography, publishing, technology and theatre (Kickstarter 2011). Another important aspect of crowdfunding is that not all websites allow project owners to offer equity to the backers of 
the projects. Instead, many offer a rewards system whereby people who pledge money receive different rewards depending upon how much they pledge. These rewards can include exclusive news and updates about the project, as well as early product releases. Crowdfunding is therefore not only a useful method of raising capital for small businesses without having to give away equity but it also provides the opportunity for businesses to engage with consumers and acquire useful feedback on early product releases before the product or service is launched to the general public (Belleflamme et al. 2011).

In addition to crowdfunding, a similar method that small businesses can use in order to raise capital is to apply for a loan through a peer-to-peer lending website. Peer-to-peer lending is similar to crowdfunding in that the loans come from people or "peers" as opposed to a bank. However, unlike crowdfunding, since it is a loan, peer-to-peer lending requires the borrowers to repay any loans with interest, just as a bank loan would. Nevertheless, this type of loan can be more beneficial because as Bartram (2011) reported, peer-to-peer lending has enabled many businesses to gain access to loans at much more favourable interest rates than banks were prepared to offer and as a result it has become a common method of obtaining a loan for businesses.

As described above, both crowdfunding and peer-to-peer lending services provide small businesses with new opportunities to raise capital through the Internet therefore enabling them to improve their financial resources and their survival prospects. There are, nevertheless a number of threats relating to this recent e-commerce innovation (Table 5.1). If the business is a start-up venture then the business idea is made widely available to a global audience who are in a position to copy the concept. This forces small enterprises to seek intellectual property protection which increases start-up costs even further and subsequently the level of risk involved. This new source of finance is also unregulated so there are threats relating to the reliability of funding sources thereby necessitating due diligence. This also entails further time and resource expenditure. A further threat is the failure to raise the necessary funds online resulting in damage to the firm's reputation and negative rather than positive word-of-mouth. These were also concerns expressed by the SMEs who participated in the focus group interviews although some of the businesses had received finance via Funding Circle.

\subsubsection{Card Payment Processing}

Another business function where the e-commerce applications offer new opportunities for small businesses is in the ability to accept credit and debit card payments via mobile devices. As reported by Howard (2013), there are several companies that are offering services that enable small businesses to accept card payments through the Internet by using an app and a card reader that connects to a smart phone or tablet. In order to be able use this technology, small businesses only require a card reader device, which is provided by the company and a smart phone or tablet with an Internet connection to run the free app. 
This technology offers many opportunities for small businesses because firstly, by enabling the acceptance of card payments over the Internet, it allows businesses that are mobile, such as taxi drivers, plumbers or pop-up shops, a simple way to accept credit or debit cards. This also reduces the threat of lost sales as more people move away from cash payments or don't have the necessary funds at the opportune moment. Secondly, some of the app's provide businesses with the ability to track sales, customer trends and inventory (Leonard 2012). This consequently, provides businesses with useful information that can help to enhance their performance through tracking popular products as well as forecasting staffing levels and materials requirements at certain times of the year based on historic data.

A further advantage of mobile payment processing is that whilst there is normally a one-off fee for the card reader, there are no monthly fees, only a percentage fee for each transaction, which the standard rate is currently $2.75 \%$ (Lunden 2013). This as a result, is a relatively small cost compared to that of traditional card readers which, as The Economist (2012) explains, can be expensive and have fixed monthly fees on top.

Moreover, the ability for small businesses to take immediate mobile card payments can also help to improve cash flow (Table 5.1). This is because, as stated by the Federation of Small Businesses (2011), $73 \%$ of small businesses were affected by late payments in the previous 12 months. Furthermore, the Federation of Small Businesses (2011) also found that $53 \%$ of small businesses spent between 1 and 6 hours each week chasing payments. These issues affect the resources available to small businesses in terms of finance, time and labour. However, by using this technology these issues can be avoided, as it allows payment to be taken at the time of the sale or delivery. One of the threats of providing an e-commerce payments capability is that new technologies such as the electronic wallet-using near-field communications (NFC) and smart phones - and other payment platforms have the potential to disrupt this payment method resulting in unnecessary expenditure on a technology that has a very low take-up or where different types of hardware and software are required. Therefore, until a common e-commerce platform is established the return on investment for SMEs may be limited. The absence of network effects (i.e. the fact that many customers weren't interested in using this payment method) was one of the key reasons given by the focus group participants for the non-adoption of this e-commerce technology.

\section{Financial Accounts}

An additional finance-related business function that can benefit from the use of ecommerce applications is financial accounts. This is where small businesses are able to manage their financial accounts via cloud based applications such as Kashflow or Clear Books.

Cloud based accountancy software provides a variety of opportunities that can be useful for many small businesses. These include the ability to access their accounting data anywhere, at anytime and on any platform, as long as there is an 
Internet connection. This can be very useful for mobile businesses as well as owner-managers who want to look at the business' finances during out of work hours. In addition to this, the financial data can be used to generate key performance reports and graphs which can help small businesses understand current performance quickly and effectively (Clearbooks 2011a; Kashflow 2012a).

Furthermore, the software can be used to set up automatic tasks such as recurring invoices and late payment reminders (Clearbooks 2011b; Kashflow 2012b). This can be used to help save time and improve cash flow, consequently avoiding the issues relating to late payments previously discussed.

Another opportunity created by an e-commerce cloud based application is that small businesses can provide their accountants with access to the accounts (Clearbooks 2011b). This can help to reduce the inconvenience of sharing the financial information with the accountant as it is readily available online. This should help to save time for the accountant and thereby lower the accountancy costs for the business.

These types of system have a further advantage in that they are available at a low monthly rate rather than a large one off cost. This reduces the burden on the financial resources of the business. Furthermore, with a monthly fee, as opposed to a one off payment, businesses will benefit from free future updates (Clearbooks 2011c; Kashflow 2012c).

Moreover, another benefit of this technology is that companies such as Kashflow allow integration with other cloud-based applications such as MailChimp. According to O'Hear (2011), this can benefit small businesses greatly by providing them with detailed information about their customers which they can then use to create targeted email marketing campaigns based on characteristics such as customer spending habits, just as larger businesses are able to do. However, there are a number of e-commerce threats relating to such systems including security concerns (Table 5.1). Many owner-managers wish to retain a high level of personal ownership over their financial information. In addition, there has to be some form of financial system in place before any data can be uploaded and this requires resources such as time, specialist administration skills and therefore money. Owner-managers therefore view such developments as an additional cost or overhead rather than an investment in labour-saving technology and enhanced efficiencies. Many of the small firms that were interviewed did not even have manual record systems in place although the medium-sized enterprises were using Sage online software (Sage One) and expressed interest in alternative e-commerce software solutions.

\subsection{Marketing}

As noted by Fuller (1994), marketing can be a problematic business function for many small businesses due to the lack of experts and specialists which are otherwise available to larger businesses. Furthermore, Stokes and Wilson (2010) 
indicated that other resource limitations, including the non-availability of finance, could also contribute to the inability of small businesses to undertake effective marketing practices. This section of the chapter will therefore examine how social networks, email marketing and search engine marketing can be used by small businesses and how e-commerce applications can enhance the marketing resources and capabilities of these firms. In addition, this study will also examine how ecommerce applications can enable small businesses to carry out market research and how they can be used to facilitate open innovation practices such as crowdsourcing.

\subsubsection{Social Networks}

In recent years, social networks have become a significant part of a consumer's lifestyle and according to McGiboney (2009) they account for $17 \%$ of total time spent on the Internet. As a result, this provides small businesses with the opportunity to utilise social networks as an effective marketing medium to engage consumers, acquire customer feedback and increase brand awareness.

One of the ways social networks can be used to engage consumers is through their advertising services such as Facebook Ads. As Bolotaeva and Cata (2011) explain, this can be a relatively inexpensive method of advertising compared to traditional approaches because, similar to other advertising platforms, businesses only have to pay if the Ads achieve results i.e. when the Ad is clicked upon. Furthermore, businesses can set a daily budget, which allows firms to control advertising expenditure (Facebook 2010). In addition to this, Facebook enables businesses to target specific consumers based upon information they provide on their Facebook accounts including location, age, birthday, interests, education and connections (Facebook 2010). This means that small businesses can focus their resources on marketing to consumers who are more likely to make a purchase therefore allowing them to make the most of their available resources.

An alternative method of marketing using social networks is to set-up profiles for the business on different social networking websites. These can then be used to acquire 'supporters' or 'followers', which will be notified as the business posts news, updates and other messages on its social networking profiles. This can be a valuable method of promoting the business as well as its products and services because it can be done with very little effort and no expense other than the short amount of time required setting it up and implementing it. This method of marketing makes it ideal for small businesses with low and/or no marketing budget. In addition to this, a major advantage of social media marketing as opposed to traditional marketing methods (such as radio, newspaper or television advertisements) is that it is very easy for consumers to share messages and content virally amongst their contacts, consequently creating a vast potential audience (Harris and Rae 2009). 
Social networks can also be used as an effective method of market research by gaining customer ideas and feedback which can then be used to assist business and product development. There is no cost involved other than the time required setting it up and implementing it. For example, a small bakery could ask its customers to vote for their preferred flavour for a featured cake. By doing this the bakery will not only know which cake is more popular and have an estimate for the number of potential sales but it could also help customers to feel more valued as their opinions are being sought after, which may lead to increased customer retention.

The interaction between businesses and consumers over social networks has become important because as Diffley et al. (2011) suggest, consumers are no longer satisfied with just being an audience for a business' marketing messages but want to have an active role in improving their products and services. They also implied that consumers have become empowered consumers or 'prosumers' who are highly knowledgeable about products and services. Businesses can therefore use social networks, unlike other methods of marketing, to engage with "prosumers' to share messages and opinions as well as encourage feedback and new ideas that can be used to improve the products and services of a business. Moreover, as indicated by Diffley et al. (2011), since consumers have trust in each other, the shared content and electronic word-of-mouth communications regarding products and services over social networks are considered to be far more trustworthy than marketing campaigns created by businesses themselves.

Social networks such as Twitter can also be used to promote the business whilst providing effective customer service. This can be achieved by answering users questions and commenting when users mention the business or its products and services. As Bernard et al. (2009) suggest, micro-blogging applications such as Twitter provide interaction and allow more personal communication to take place between the users due to the maximum character length. This is important because as Kozinets (1999) notes, this type of conversational engagement between businesses and consumers has become increasingly popular (as consumers appreciate the personal messages) therefore improving the relationship between the business and the customer. In addition to this, the customer's contacts will also see the messages, which subsequently help to promote the business and improve brand awareness.

In order to manage their social media marketing, small businesses can use e-commerce applications such as HootSuite. HootSuite is a social media management tool that enables businesses to manage multiple social network accounts from one application (HootSuite 2013a). In addition to this, as described by Peters (2011), HootSuite also provides a number of useful features that can assist with social media marketing including the ability to schedule posts and the provision of analytics that measure user activity on social networks. A further feature of HootSuite is that it enables businesses to setup custom searches to monitor social networks when users mention the business or brand (HootSuite 2013b). This can be helpful to businesses wanting to provide customer service over social networks as discussed above. Moreover, due to the potentially limited financial resources 
available to small businesses, it is important to mention that HootSuite also offers scalable plans including a free plan depending upon the level of features desired. This is beneficial because whilst the free plan does not include all of the advanced features of the paid plans, small businesses can utilise the free plan until the required financial resources are available or the return on social marketing becomes significant enough for them to upgrade to the more advanced paid plans (HootSuite 2013a).

\subsubsection{Email Marketing}

As stated by Gopal et al. (2006), email marketing has become an important part of advertising for many businesses due to the ability to tailor messages to target specific consumer segments and it is very low cost in comparison to other methods of advertising. This is important because small businesses do not have the financial resources to spend large amounts of money on advertising campaigns. In addition to this, as noted by Reed (2010), email marketing can also be used by small businesses as an effective way to achieve marketing objectives such as building relationships with existing customers, encouraging repeat business and acquiring new customers.

In order to carry out effective email marketing there are several e-commerce applications that small businesses can use to assist them which can help to improve both their marketing resources and performance. According to Reed (2010), Internet applications such as MailChimp and Campaign Monitor provide small businesses with a variety of features that can help to manage and optimise their email marketing campaigns. In addition to this, Reed (2010) explains how the use of these applications requires very little technical knowledge, which is useful because as previously mentioned, many small businesses may not have specialist skills or the expert knowledge available to them.

Both MailChimp and Campaign Monitor offer a variety of features that can be beneficial to small businesses including the ability to design and create emails using their pre-designed templates and a simple-to-use in-built design editor (MailChimp 2012a; Campaign Monitor 2013a). This can be helpful for small businesses that do not have the required skills to create professionally designed emails because instead of having to pay a designer to create them, they can use the in-built design editor. Another useful feature of these applications is that they enable small businesses to produce a mailing list as well as "Subscribe" and "Unsubscribe" forms that link to the list. This automates the process adding and removing users from the list (MailChimp 2012b; Campaign Monitor 2013b). This is useful because it means that once an email list has been setup, there is no need to manage the list manually, allowing small businesses to spend their limited time on other tasks.

A further important feature that can benefit small businesses is the ability to use either of these applications to track important performance data and information about each of the email campaigns. Amongst other things, this data includes how 
many of the emails were opened, who opened them, which links they clicked on and what device the email was viewed upon (MailChimp 2012c; Campaign Monitor 2013c). This can then be used to analyse consumer behaviour so that future email campaigns can be improved. Furthermore, this data will also enable small businesses to segment their email list to target different consumers based on details such as their location or levels of engagement. By segmenting the emailing list in this way businesses can then provide more relevant content to target each segment in future emails, which should help to improve consumer engagement. Furthermore, both MailChimp and Campaign Monitor integrate with tools such as Google Analytics, which allows small businesses to view other performance data such as conversions on their website and return on investment (MailChimp 2012c; Campaign Monitor 2013c). This is important, because small businesses will be able to compare the number of conversions and return on investment to other methods of marketing to ensure they are making the most of their limited resources.

\section{Search Engine Marketing}

Another important method of marketing that should be considered for small businesses is to drive potential customers to their website using search engine marketing (SEM). SEM is important because according to Fleishman-Hillard (2012), $89 \%$ of consumers rely upon search engines to help make purchasing decisions. In addition to this, SEM can be used to target consumers that are actively searching for particular products or services and are therefore further along the purchasing process than other forms of marketing. If carried out correctly, SEM can be used to identify and convert these consumers into actual sales, resulting in a good return on investment, which is ideal for small businesses with only limited resources.

Murphy and Kielgast (2008) describe the two different types of SEM as: pay for performance, whereby businesses pay to list website advertisements (Ads) alongside organic (non-paid) search results; and search engine optimisation, which involves optimising a website to be displayed within the organic search results.

In order to carry out pay for performance marketing, small businesses can use search engine advertising applications such as Google Adwords. Google Adwords, like Facebook Ads, allows businesses to target consumers based on specific parameters. Google Adwords enables businesses to create Ads that will display on the search results for specific keywords and phrases that they are prepared to bid for (Google 2010a). These keywords and phrases are identified by the business as the words or phrases that potential customers may type into search engines in order to find their business, product or service. In addition to this, Google Adwords allows businesses to target their potential customer further, by setting other parameters to decide when their Ads will be displayed. These parameters can be based on location, device searched from, day of the week or even, time of the day (Google 2010b). 
Google Adwords can be a useful method of advertising for small businesses because, as already mentioned, it allows them to target consumers who are actively searching for products and services which suggests they are more likely to make a purchase. Furthermore, unlike other forms of traditional advertising, businesses only have to pay for Ads that have resulted in interaction from consumers i.e. when they click on the Ad. This can help to improve return on investment, which is important for small businesses that may only have a limited marketing budget. In addition to this, Google Adwords provides performance statistics for each of the keyword or phrases the business bids on, including the number of clicks, impressions, click-through rate and average position of the Ad (Google 2010c). These can then be used to optimise the Ads to further improve the return on investment. Similar to Facebook Ads, Google Adwords also allows businesses to set a maximum daily budget, which can be useful for small businesses that only have limited budgets and consequently need control over advertising expenditure.

Whilst some methods of advertising such as newspaper or radio advertisements will only reach a potential audience on a local or even national scale, small businesses can use Google Adwords to target a global audience. This can be vital for small businesses that have a niche' product and therefore could benefit from an increase in potential customers by targeting a global niche'. For example, a small business advertising large shoes for people with very large feet will only have a small potential customer base nationally and even smaller locally. However, by using SEM such as Google Adwords they can advertise globally, which will increase the potential customer base significantly (a small niche' segment becomes a very large global niche' segment).

The alternative to SEM is to use search engine optimisation (SEO) which as defined by Grappone and Couzin (2006) as the variety of tasks that improve a website's presence on search engines. One of the major benefits of SEO, noted by Amerland (2011), is that like pay-per-click advertising such as Google Adwords, it can drive targeted consumer traffic actively looking to purchase, to a business' website. Yet, unlike pay-per-click advertising, SEO has no cost other than the time required to implement it. This consequently makes it an ideal method of advertising for a small business with no available marketing budget.

In order help implement SEO practices successfully, small businesses can utilise e-commerce applications such as Google Webmaster Tools. Google Webmaster Tools provides businesses with comprehensive data about their website useful for SEO, including internal and external links, search queries, crawl errors and indexing results. In addition to this, it also enables businesses to submit sitemaps directly to Google (Google 2010d). These features can assist small businesses with optimising their website in order to improve its presence on search engines. It is also important to note that Google Webmaster 'Tools' is a free service, which also makes it suitable for small businesses with no available marketing budget. Moreover, Google provides various types of help and resource support that enables people with little knowledge or expertise to learn how to use 
Webmaster Tools. This is beneficial for small businesses that may lack the necessary expertise.

SEM has become an important marketing consideration for many businesses, due to the high proportion of consumers using search engines when making purchasing decisions. However, whilst both types of SEM can be effective methods of marketing, the use of advertising applications such as Google Adwords, require an available advertising budget and therefore may not be suitable for all small businesses. SEO on the other hand, has no direct cost and the use of Internet applications such Google Webmaster Tools can further help to enhance a business' SEO efforts and overall marketing effectiveness.

The main e-commerce opportunity that social networking, e-mail and search engine optimisation creates for small businesses is the ability to execute abovethe-line advertising campaigns and to sell products and services in global segments that were previously considered inaccessible (Table 5.1). There are, however, a number of e-commerce threats in that viral word-of-mouth marketing can be negative as well as positive particularly if executed poorly. If a campaign is successful it can generate very large volumes of business that can exceed the capacity of a small business that is used to a slow build-up of orders based on traditional marketing methods. This can cause customer dissatisfaction and a loss of reputation. There are also threats relating to various forms of fraud (including 'click' fraud) whilst the loss of content ownership to social media sites has also caused concerns amongst SME owner-managers. Finally, the web has become an extremely crowded marketplace, so differentiating a small company brand can involve a disproportionate level of resource input. The focus group participants all performed some form of Internet marketing with different levels of success and sophistication. All the firms had at least reached stages one and two (e-mail and website marketing) in Dini and Nachira's (2007) model, with some accepting online payments (stage three). However, none of the firms had managed to exploit a global niche' segment.

\subsection{Market Research}

Another important business function related to marketing is the collection of market research data. Market research can be an issue for small businesses because as Stokes and Wilson (2010) describe, whilst the collection of secondary data can be less costly and quickly obtainable, it can often be outdated and not specific enough for certain businesses. Whereas primary data may be more up-to-date and specific, it is also more costly and time consuming. As a result, small businesses may find it difficult to collect market research data due to the limited availability of time and financial resources. However, by utilising certain e-commerce applications, small businesses can collect market research both effectively and efficiently, despite their limited resources. 
As already explained, one method of collecting market research is to use social networks to gain customer feedback and encourage them to share new ideas. Whilst this does not have a direct cost, this method can be time consuming and therefore small businesses could consider the use other e-commerce applications, such as Google Consumer Surveys and SurveyMonkey instead.

Google Consumer Surveys allow businesses to create custom online surveys that are then used to gain consumer insight. This is achieved by asking users to answer questions from the survey in order to access premium content on the Internet, such as news articles or videos. Once the survey has been created responses can be virtually immediate and completion time is only expected to be 7 days (Google 2010e). In addition to this, Google Consumer Surveys allow businesses to target respondents by choosing a specific audience based on options including particular demographic or geographic characteristics (Google 2010f). Moreover, Google automatically aggregates and analyses the responses straight away, allowing businesses to view results immediately (Google 2010g). This is beneficial for small businesses because it enables them to collect primary research, which is both up-to-date and from specific respondents, in a timely manner that requires no time spent collecting or analysing the actual data. Furthermore, with a price of $\$ 0.10$ per response, this is a relatively cheap method of market research (Google 2010g).

An alternative Internet application that small businesses can use to conduct market research is SurveyMonkey. Similar to Google Consumer Surveys, SurveyMonkey enables businesses to create a survey and gain responses from a specific audience based upon particular criteria such as gender, age, marital status and household income (SurveyMonkey 2009a). SurveyMonkey also provides other features, including real-time response reporting, custom branding and the provision of a survey URL, allowing businesses to link the survey to their emails, social network profiles and websites (SurveyMonkey 2009b). This is particularly useful because unlike Google Consumer Surveys, SurveyMonkey provides a free plan whereby businesses are able to create the survey but have to collect the responses themselves. Therefore, small businesses can link the survey to their website in order to gain responses. This Internet application can be beneficial for small businesses because it enables them to create a survey that can then be used to collect primary research, either by themselves or by SurveyMonkey, in a relatively cheap and effective manner.

Another e-commerce application that small businesses can use to conduct a form of market research is Google Analytics. Google Analytics is a free application that collects and analyses data about visitors on a particular website, including the number of visitors, page views and average time spent on the site. In addition to this, Google Analytics can be used to measure the number of sales and conversions (such as completed online contact forms) on a particular website (Google 2010g). Businesses can therefore use Google Analytics as a method of market research in order to understand consumer behaviour and engagement with their website. This information can then be used to implement changes that can improve the online sales or other forms of conversions through the website. Not 
only is this useful to small businesses by improving the effectiveness of their website but it can also help free-up financial resources that are required for other methods of market research. This is important because market research can lead to innovation and the development of both new and existing products which, as noted by Stokes and Wilson (2010), is necessary if small businesses wish to stay competitive and ultimately survive.

The use of e-commerce applications that collect data and information from consumers can further benefit small businesses by facilitating open innovation practices such as crowdsourcing. Crowdsourcing, as first coined by Howe (2006), is a practice that utilises the Internet to harness resources such as the time, ideas, skills and the expertise of many people. It can also be considered as an example of open innovation which, as described by Chesbrough (2006), involves the use of external ideas to achieve innovation. Small businesses can take advantage of crowdsourcing and open innovation by using Internet applications such as social networks to encourage people to share ideas; Google Analytics to gain an insight into consumer's online behaviour; and even payment processing technologies such as iZettle to access data and information about consumer spending, tastes and interests. Small businesses can then utilise the ideas and data collated through e-commerce applications to effectively use consumers as part of the research and development process. This enables small businesses to access a far greater research and development potential than would otherwise be possible due to their limited available resources. Furthermore, according to von Hippel (2006), involving users of a product in this process can also be advantageous because research undertaken in laboratories can ignore some of the issues that can only be identified through user interaction.

As Sandulli and Chesbrough (2009) discuss, an example of a business using open innovation through crowdsourcing is Threadless.com. Threadless.com does this by asking people to submit their own designs for T-shirts. These T-shirt designs are then voted upon to find the most popular design, which is then produced. This is useful for Threadless.com because in addition to not incurring the cost of designing the T-shirt themselves, by getting people to vote on their favourite designs, they can also understand current consumer trends and tastes without having to conduct any market research themselves.

The use of e-commerce applications to facilitate crowdsourcing should be an important consideration for many small businesses because not only does it provide the opportunities to significantly increase their market research capabilities but it can also help to support innovation, which could underpin the future success of a business.

One of the threats of crowdsourcing and open source innovation is that any competitive advantage achieved is short-lived because the ideas are easily and quickly copied from the public domain resulting in a need for the small business to be constantly updating their product/service portfolio and any differentiation advantage is therefore temporary and transient (Table 5.1). A significant proportion of the focus group participants did not undertake formal market research viewing this as time-consuming and requiring specialist skills although they did informally collect customer feedback. 


\subsection{Operations}

E-commerce applications can also be used by small businesses to assist with business functions related to operations. According to Stokes and Wilson (2010), one of the major problems for small businesses is finding premises. This can be problematic for two reasons. First, not only can it be difficult to find a suitable location but there is also the second issue of limited financial resources and the prohibitive cost of renting an office or retail outlet. As a result, many small businesses now operate as virtual enterprises (Davidow and Malone 1992) and have taken advantage of e-commerce applications that have enabled them to operate in this way.

This reduces the need for businesses to have dedicated offices and physical storefronts, as employees can work from anywhere with an Internet connection, including their home. As explained by Radut (2009), the benefits of using these technologies to operate as a virtual enterprise include reduced costs, increased flexibility, improved asset utilisation and scalability. These benefits help make virtual businesses leaner and consequently more competitive.

The growth of M-commerce (mobile commerce) and the widespread adoption of smart phones and tablet computers (plus the impending roll out of $4 \mathrm{G}$ networks), has greatly facilitated this transformation. Small firms can now operate virtually using wireless and fixed line Internet connections (Davenport and Pearlson 1998).

In order for small businesses to operate in this way there are a number of ecommerce applications that they can utilise. Voice over IP applications such as Skype allow employees to communicate for free through calls over the Internet. In addition to this, Skype also provides users with several other features (some at a cost) including calls to landlines and mobiles, video calls, dial in number, screen and file sharing, instant messaging and group calls (Skype 2009). These features can therefore be used to communicate effectively with key stakeholder groups such as employees, suppliers and customers.

Another set of e-commerce applications that a small business can utilise is Google Apps for Business. Google Apps for Business is a cloud based service, which provides businesses with several applications that facilitate email, calendar and file sharing, for a relatively low monthly cost (Google 2010f). These applications can be beneficial for small businesses as they enable employees to communicate, collaborate and share data between each other efficiently. However, this is especially important for virtual enterprises because employees can be in different geographic locations and therefore cannot discuss and exchange things in the same way that they would if they were in an office environment.

An additional e-commerce application that small businesses can use to assist collaboration between employees is Asana. Asana is a cloud based task management application that allows users to easily create, assign, comment and follow tasks between them and their team (Asana 2013). As well as assisting employee collaboration, this application can also be used to manage and review both task and 
employee progress. Furthermore, because it can be accessed over the Internet, employees can use it despite being in different locations.

The use of these Internet applications can help small businesses to work effectively, especially those without dedicated offices. As already mentioned, operating as a virtual enterprise or having a virtual office can be important for small businesses that have limited financial resources and cannot afford their own dedicated premises (Table 5.1). A further benefit of operating in this way, as noted by Cascio (2000), is that it allows businesses to employ people with specialist skills and expertise from all over the world rather than being limited to people based in a particular area or country.

One of the threats of operating virtually is that the benefits of-face-to-face contact and trust are lost and robust relationships are not consolidated. SME owners have the advantage of being close to customers, employees and suppliers and this advantage can be diluted through virtual working. Many of the ownermanagers of the small and medium-sized firms in the focus groups didn't trust their employees with respect to teleworking which has still to take root in the UK. Some of these small business owners (particularly Herefordshire) also operated in rural areas where Internet connections were poor (the digital divide) and therefore virtual working wasn't feasible.

\subsection{Human Resources (HR)}

As discussed by Stokes and Wilson (2010), a common HR issue amongst small businesses is that they often lack specialist skills and expertise. As a result, this could cause small businesses to make the wrong decisions when faced with problems or opportunities where they lack experience or knowledge. This could consequently lead to the wrong decisions being made and resources being wasted.

In order to solve this issue, small businesses can make use of e-commerce applications such as Clarity. Clarity allows users to choose a specific expert from a particular profession and schedule a telephone call with them, for which they pay a specified rate per minute (Clarity 2013). This provides small businesses with the opportunity to gain advice from experts who have particular knowledge or experience that they could benefit from. As a result of this, small businesses are able to make more informed decisions which ultimately benefit the business and help to reduce the likelihood of resources being wasted. However, one of the threats of this form of human resourcing is that it bypasses valuable and trusted word-of-moth recommendations from face-to-face networks (Table 5.1). According to the focus group interviewees, trying to evaluate the level of social capital within a virtual environment was very difficult and could lead to recruitment decisions that would threaten the sustainability of the business. 


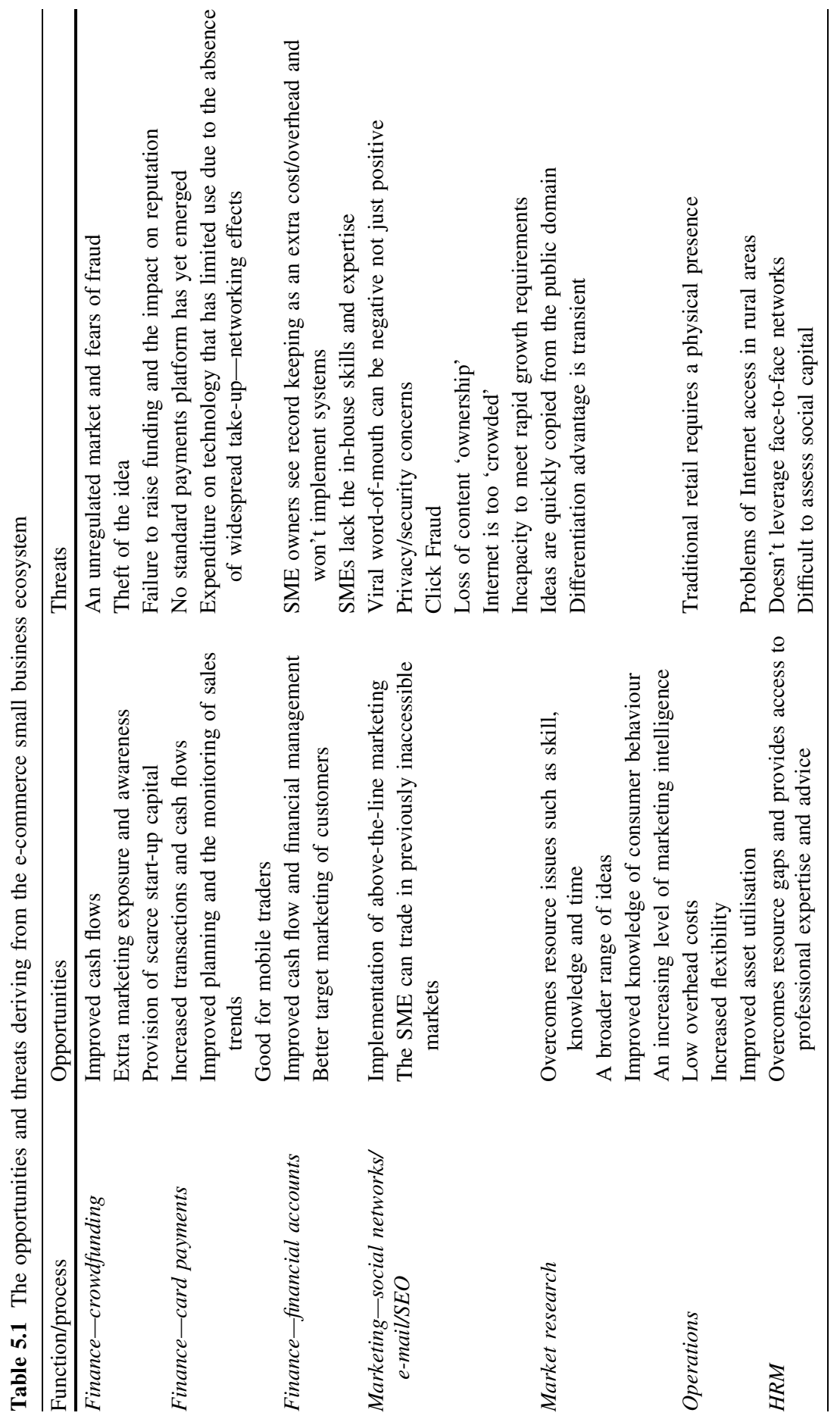




\subsection{Conclusion}

The purpose of this chapter was to investigate how ecosystem theory could be applied to small, medium enterprises and how these firms could utilise e-commerce Internet applications to enhance and improve resource sourcing and deployment. The empirical research undertaken with small, medium-sized retail service firms in the Herefordshire and Worcestershire areas also revealed a very positive response to the opportunities highlighted by the ecosystem model. At least $50 \%$ of the service firms that were interviewed in the three focus groups were using functional e-commerce tools similar to the ones analysed in the chapter; particularly with respect to Internet marketing and the adoption of electronic payment methods. On the other hand, many small firms were suffering from Internet connectivity problems in the rural areas of Herefordshire and were not able to fully exploit the opportunities of having an e-commerce capability. Security and content ownership were ongoing concerns of most of the small firms that were interviewed. The age ranges of the owner-managers also had an impact on their e-commerce adoption strategies, with the older generation seeing technology as a threat rather than a resource-opportunity to be exploited.

Finally, as this chapter has shown, there are a wide variety of e-commerce applications available to small businesses. Whilst not all of these may be applicable to every business (none of the interviewed firms had reached the final digital ecosystem stage in Dini and Nachira's 2007 model Fig. 5.1) it is clear that these applications provide many opportunities for small businesses to enhance their overall performance and to off-set threats to their survival prospects. The ecosystem approach could also be seen to help small businesses overcome barriers to start-up and market entry.

\section{References}

Amerland D (2011) Brilliant search engine optimisation. Pearson Education Limited, Harlow Asana (2013) Asana-product tour. http://asana.com/product. Accessed 22 Apr 2013

Bank of England (2000) Finance for small firms. Bank of England, 7th Report

Bartram P (2011) Peer-to-peer lending networks offer a new source of capital for smaller businesses. Peter Bartram examines their structure and benefits for the world's finance teams. Financial Management. Business Source Premier. Accessed 2 Mar 2013 (Online)

Belleflamme P, Lambert T, Schwienbacher A (2011) Crowdfunding: tapping the right crowd. CORE Discussion Paper No. 2011/32. http://www2.dse.unibo.it/dsa/seminari/610/Crowd funding_BLS_13Feb2011.pdf. Accessed 25 Mar 2013

Bernard JJ, Zhang M, Sobel K, Chowdury A (2009) Twitter power: tweets as electronic word of mouth. J Am Soc Inform Sci Technol 60(11):2169-2188. http://onlinelibrary.wiley.com/doi/ 10.1002/asi.21149/full. Accessed 24 Mar 2013 (Online)

Bolotaeva V, Cata T (2011) Marketing opportunities with social networks. J Internet Soc Networking Virtual Commun. http://www.ibimapublishing.com/journals/JISNVC/2011/4098 60/409860.pdf. Accessed 14 Apr 2013 
Campaign Monitor (2013a) Beautiful email marketing reports. http://www.campaignmonitor. com/features/report/. Accessed 8 Apr 2013

Campaign Monitor (2013b) Design beautiful emails. http://www.campaignmonitor.com/features/. Accessed 8 Apr 2013

Campaign Monitor (2013c) Manage subscribers and grow your audience. http://www. campaignmonitor.com/features/subscribers/. Accessed 8 Apr 2013

Cascio WF (2000) Managing a virtual workplace. Acad Manag Executive 14(3):81-90

Chesbrough H (2006) Open business models: how to thrive in the new innovation landscape. Harvard Business School Press, Boston

Clarity (2013) Clarity—get great advice. https://clarity.fm/faq. Accessed 22 Apr 2013

Clearbooks (2011a) Financial accounting \& reporting. http://www.clearbooks.co.uk/tour/ financial-accounting-reporting/. Accessed 27 Mar 2013

Clearbooks (2011b) Manage contacts, customers \& suppliers online. http://www.clearbooks.co. uk/tour/manage-contacts-customers-suppliers-online/. Accessed 27 Mar 2013

Clearbooks (2011c) Online accounting software for your Mac \& PC. http://www.clearbooks.co. uk/tour/online-accounting-software/. Accessed 27 Mar 2013

Cressy R, Toivanen O (2001) Is there adverse selection in the credit market? Venture Cap 3(3):215-238

Davenport TH, Pearlson K (1998) Two cheers for the virtual office. Sloan Manag Rev 39(4):51-65

Davidow WH, Malone MS (1992) The virtual corporation: structuring and revitalizing the corporation for the 21st century. Harper Business, New York

Diffley S, Kearns J, Bennett W et al (2011) Consumer behaviour in social networking sites: implications for marketers. Ir J Manag 30(2):47-65

Dini P, Nachira F (2007) The paradigm of structural coupling in digital ecosystems. In: Corallo A, Passiante G, Prencipe A (eds) The digital business ecosystem. Edward Elgar Publishing Limited, Cheltenham, pp 33-38

Facebook (2010) Targeting options. Facebook Help Center. https://www.facebook.com/help/ 131834970288134/. Accessed 12 Apr 2013

Fawcett SE, Magnan GM, McCarter MW (2008) Benefits, barriers, and bridges to effective supply chain management. Supply Chain Manag Int J 13(1):35-48

Federation of Small Businesses (2011) Late payments. http://www.fsb.org.uk/policy/rpu/london/ assets/late\%20payment\%20july\%202011.pdf. Accessed 20 Mar 2013

Fleishman-Hillard (2012) Understanding the role of the Internet in the lives of consumers: 2012 digital influence index annual global study. http://push.fleishmanhillard.netdna-cdn.com/dii/ 2012-DII-White-Paper.pdf. Accessed 17 Apr 2013

Fuller PB (1994) Assessing marketing in small and medium-sized enterprises. Eur J Mark 28(12):34-49

Google (2010a) Google adwords—online advertising by google. http://www.google.com/ adwords/how-it-works/faq.html. Accessed 11 Apr 2013

Google (2010b) Google analytics analysis tools-google analytics. http://www.google.com/ analytics/features/analysis-tools.html. Accessed 19 Apr 2013

Google (2010c) Google analytics feature list—google analytics. http://www.google.com/ analytics/features/index.html. Accessed 14 Apr 2013

Google (2010d) Google consumer surveys: how it works. http://www.google.com/insights/ consumersurveys/how. Accessed 18 Apr 2013

Google (2010e) Google consumer surveys: pricing. http://www.google.com/insights/consumer surveys/pricing. Accessed 18 Apr 2013

Google (2010f) Products—google apps for business. United Kingdom. http://www.google.com/ intl/en_uk/enterprise/apps/business/products.html. Accessed 23 Apr 2013

Google (2010g) Webmaster tools help. http://support.google.com/webmasters/?hl=en. Accessed 18 Apr 2013

Gopal RD, Tripathi AK, Walter ZD (2006) Economics of first-contact email advertising. Decis Support Syst 42(3):1366-1382 
Grappone J, Couzin G (2006) Search engine optimization: an hour a day. Wiley Publication Inc, Indianapolis

Harris L, Rae A (2009) Social networks: the future of marketing for small business. J Bus Strategy 30(5):24-31

HootSuite (2013a) social media management plans-hootsuite social media management. http:// hootsuite.com/plans. Accessed 6 Apr 2013

HootSuite (2013b) Social network management-hootsuite social media management. http:// hootsuite.com/features/social-networks. Accessed 6 Apr 2013

Howard B (2013) Smartphone card payment systems seek small firms. BBC. http://www.bbc.co. uk/news/business-21087283. Accessed 4 Mar 2013

Howe J (2006) The rise of crowdsourcing. http://www.wired.com/wired/archive/14.06/crowds. html. Accessed 20 Apr 2013

Hyeyoung K, Jae-nam L, Jaemin H (2010) The role of IT in business ecosystems. Commun ACM 53(5):151-156

Johnson ME (2006) Supply chain management: technology, globalization and policy at a crossroads. Interfaces 36(3):191-193

Kashflow (2012a) Accounting software features-credit control. http://www.kashflow.com/ features/credit-control/. Accessed 27 Mar 2013)

Kashflow (2012b) Accounting software features - reports. http://www.kashflow.com/features/ reporting/. Accessed 27 Mar 2013

Kashflow (2012c) Accounting software-pricing. http://www.kashflow.com/pricing/. Accessed 27 Mar 2013

Kickstarter (2011) Guidelines-Kickstarter. http://www.kickstarter.com/help/guidelines. Accessed 18 Mar 2013

Kozinets RV (1999) E-tribalized marketing?: the strategic implications of virtual communities of consumption. Eur Manag J 17(3):252-264

Leonard H (2012) BII mobile insights: how mobile payment solutions increase sales. business insider. http://www.businessinsider.com/bii-mobile-insights-how-mobile-payment-solutionsincrease-sales2-2012-10. Accessed 4 Mar 2013

Lunden I (2013) PayPal here is coming to the UK, its first mobile payment market in Europe, armed with a new way to read your card. TechCrunch. http://techcrunch.com/2013/02/21/ paypal-here-is-coming-to-the-uk-its-first-market-in-europe-armed-with-anew-way-to-read-your-card/. Accessed 4 Mar 2013

MailChimp (2012a) Custom forms MailChimp. http://mailchimp.com/features/custom-forms/. Accessed 8 Apr 2013

MailChimp (2012b) New editor. http://mailchimp.com/features/new-editor/. Accessed 8 Apr 2013

MailChimp (2012c) Reports overview. http://mailchimp.com/features/reports-overview/. Accessed 8 Apr 2013

McGiboney M (2009) Nielsen reports 17 percent of time spent on the internet in august devoted to social networking and blog sites, Up from 6 Percent a year ago. The Nielsen Company. http://blog.nielsen.com/nielsenwire/wp-content/uploads/2009/09/InternetSpend_ SocialNetworks.pdf. Accessed 23 Mar 2012

Moore JF (1993) Predators and prey: a new ecology of competition. Harvard Bus Rev 71(3):75-86

Murphy HC, Kielgast CD (2008) Do small and medium-sized hotels exploit search engine marketing? Int J Contemp Hosp Manag 20(1):90-97

O'Hear S (2011) Kashflow wants to make a monkey of email marketing, integrates with MailChimp. TechCrunch. http://techcrunch.com/2011/04/13/kashflow-wants-to-make-amonkey-of-email-marketing-integrates-with-mailchimp/. Accessed 4 Mar 2013

Ordanini A (2009) Crowd funding: customers as investors. Wall Str J. http://online.wsj.com/ article/SB123740509983775099.html. Accessed 12 Mar 2013

Peters M (2011) How to: use hootsuite as a marketing tool. Mashable. http://mashable.com/2011/ 05/11/hootsuite-marketing-guide/. Accessed 1 Apr 2013 
Poon S, Jevons C (1997) Internet-enabled international marketing: a small business network perspective. J Mark Manag 13(1):29-41

Radut C (2009) Virtual corporations, enterprise and organisation. Econ Seria Manag 12(1):121-135

Reed J (2010) Get up to speed with online marketing: how to use websites, blogs social networking and much more. Pearson Education Limited, Harlow

Sandulli F, Chesbrough H (2009) The two faces of open business models. http://infojustice.org/ download/gcongress/open_business_models/sandulli\%20article.pdf. Accessed 20 Apr 2013

Skype (2009) Features. http://www.skype.com/en/features/. Accessed 23 Apr 2013

Stokes D and Wilson N (2010) Small Business Management and Entrepreneurship. (6th Ed) Cengage Learning

SurveyMonkey (2009a) Audience: target surveys takes on our research panel. http://www. surveymonkey.com/mp/audience/our-survey-respondents/. Accessed 18 Apr 2013

SurveyMonkey (2009b) Survey software tool for free professional research. http://www. surveymonkey.com/mp/take-a-tour/. Accessed 18 Apr 2013

The Economist (2012) A wealth of wallets, pp 15-18. 19 May 2012

von Hippel E (2006) Democratizing innovation. The MIT Press, Cambridge 